\title{
Information Structure and the Accessibility of Clausally Introduced Referents*
}

\author{
Michael Hegarty \\ Louisiana State University \\ mhegar1@1su.edu
}

\author{
Jeanette K. Gundel \\ University of Minnesota \\ gunde003@tc.umn.edu
}

\author{
Kaja Borthen \\ NTNU, Trondheim \\ kaja.borthen@hf.ntnu.no
}

\section{Introduction}

When certain entities are introduced into a discourse by a clause (or sequence of clauses), they are accessible to immediate subsequent reference with demonstrative pronouns, but comparatively inaccessible to reference with the personal pronoun $i t$, as noted by Webber (1988, 1991), among others. ${ }^{1}$

For example, when the first sentence in (1a) introduces the situation of there being a snake on the speaker's desk, the demonstrative pronoun that in the second sentence can refer to this situation; and with this second mention of the situation, the pronoun it in the third sentence can also refer to this situation. But in (1b), the personal pronoun it cannot be felicitously used for immediate subsequent reference to the situation introduced by the first sentence; it is more naturally interpreted as referring to the snake itself.
a. There was a snake on my desk. That scared me. It scared my office-mate too.
b. There was a snake on my desk. It scared me. [it $=$ the snake, not the situation]

In (2), an act introduced into the discourse is subject to immediate subsequent reference using that, but $i t$ is more naturally interpreted as referring to the leaf collection, not the act of destroying it.

(2) A: Max destroyed his leaf collection last night.

B: That was dumb. [that can refer to the act of destroying the leaf collection]

It was dumb. [it = the leaf collection, not the act of destroying it]

In (3), the same referential behavior is exhibited by the fact, introduced in the opening quote, that Mr. Montanarelli and his associates believe Ms. Lewinsky, and the court does not.

\footnotetext{
"The paper is submitted to a special issue of "Theoretical Linguistics", edited by Klaus von Heusinger and Kerstin Schwabe

- Our examples here will be from English, although similar restrictions on pronominal reference to clausally introduced entities can be found in other languages.
} 
(3) a. "We believe her, the court does not, and that resolves the matter," Mr. Montanarelli said today of Ms. Lewinsky's testimony that she had an independent recollection of the date. (New York Times, May 24, 2000)

a'. "We believe her, the court does not, and it resolves the matter," Mr. Montanarelli said today of Ms. Lewinsky's testimony that she had an independent ...

The same can be observed for a proposition in (4), and a complex situation in (5).

(4) ... University of Michigan psychologists David Lykken and Auke Tellegan ... speculated in their analysis of twin studies that "trying to be happier [may be] as futile as trying to be taller and therefore is counterproductive." ... Do we really believe that Romanian orphan babies left alone in their beds will have the same potential for happiness as those raised by caring parents of ample means? That is precisely what quotes such as those above will be taken to imply.

(Cook-Deegan, Robert. 2001. Hype and hope. American Scientist 89.1:62-64.)

\# It is precisely what quotes such as those above will be taken to imply.

(5) "The fact that you can get a sheep or a mouse that looks normal," said Stuart Newman, a developmental biologist at New York Medical College, "doesn't mean that some subtle things haven't gone wrong in brain development that you wouldn't necessarily notice in a sheep, but you would in a human ... Cloned humans might show higher rates of cancer or other diseases, but we'd only find out by cloning them and waiting to see if disaster strikes.

None of this means, however, that cloning services won't someday be marketed to desperate people-or even that human cloning isn't going on right now. (Talbot, Margaret. February 4, 2001. New York Times Magazine, Section 6, p.45.)

\# None of it means, however, ...

In (6), that refers to the proposition or statement that the poodle is one of the most intelligent dogs around. The pronoun $i t$ would have been infelicitous here. ${ }^{2}$

(6) A: I read somewhere that the poodle is one of the most intelligent dogs around.

B: well uhm..I definitely wouldn't dispute that. (Switchboard Corpus, Dialog 2019)

B': ??well uhm..I definitely wouldn't dispute it.

This paper will examine the role of various factors in affecting the salience, and hence the accessibility to pronominal reference, of entities introduced into a discourse by a full clause. We begin with the premise that the possibility of pronominal reference with it versus that depends on the cognitive status of the referent, in the sense of Gundel, Hedberg and

2 In (6B), stress can fall on the demonstrative pronoun, or elsewhere in the utterance. In (6B'), in contrast, the personal pronoun it cannot bear stress. The point here is that (6B') is infelicitous with any stress pattern. 
Zacharski (1993). This formulation of the problem provides grounds for an explanation of the data presented above, and provides a framework within which we examine the role of various other factors in promoting the salience of a clausally introduced entity, including the information structure of the utterance in which the entity is introduced. For entities introduced by clausal complements to bridge verbs, we show that the information structure of the utterance introducing the entity has a partial, or one-sided, effect on the salience of the entity. When the complement clause is focal, the salience of the entity depends only on its referential givenness-newness (in the sense of Gundel 1988, 1999b), as we would expect. But when the complement clause is ground material, the salience of an entity introduced by the clause is enhanced. Other factors, including the presuppositionality of factive and interrogative complements, also serve to enhance the salience of entities introduced by complement clauses.

\section{The Givenness Hierarchy}

The contrasts noted in the previous section can be insightfully formulated in terms of proposals made by Gundel, Hedberg and Zacharski (1993, and earlier work) regarding the relationship between referring forms and speaker assumptions about the cognitive status (memory and attention state) of a referent on the part of the addressee.

Gundel, Hedberg and Zacharski propose that determiners and pronouns constrain possible interpretations of nominal forms by conventionally signaling the cognitive status that the intended referent is assumed to have in the mind of the addressee. This helps solve a general problem posed by the fact that the descriptive content encoded in the form of a referring expression typically underdetermines the intended referent of the expression on a particular occasion of use. For example, in (7), the content words of the phrase these primitive reptiles do not uniquely determine which primitive reptiles are being referred to, but the determiner these serves to restrict possible referents to ones that are currently activated (that is, in working memory) for the addressee.

(7) A restudy of pareiasaurs reveals that these primitive reptiles are the nearest relatives of turtles. (M.S.Y. Lee, The origin of the Turtle Body Plan. Science, v.261, 1993, 1649).

Gundel, Hedberg and Zacharski identify six different cognitive statuses (under a total linear order, as discussed below). The array of statuses is called the Givenness Hierarchy:

Figure 1. The Givenness Hierarchy $(\mathrm{GH})$ and associated forms in English

\begin{tabular}{|c|c|c|c|c|c|c|c|c|}
\hline $\begin{array}{l}\text { in } \\
\text { focus }\end{array}$ & $>$ & activated & $>$ & familiar & $>$ & $\begin{array}{l}\text { uniquely } \\
\text { identifiable }\end{array}$ & referential & $\begin{array}{c}\text { type } \\
>\quad \text { identifiable }\end{array}$ \\
\hline$\{i t\}$ & & $\left\{\begin{array}{l}\text { this } \\
\text { this } \mathrm{N}\end{array}\right\}$ & & $\{$ that $\mathrm{N}\}$ & & $\{$ the $\mathrm{N}\}$ & $\{$ indefinite this $\mathrm{N}\}$ & $\{a \mathrm{~N}\}$ \\
\hline
\end{tabular}


Statuses on the hierarchy correspond to memory and attention states, ranging from most restrictive, 'in focus', to least restrictive, 'type identifiable'. The forms serve as processing signals which assist the addressee in restricting possible interpretations. In (8) below, for example, the nominal forms used signal the restrictions on interpretation shown at right. ${ }^{3}$

I couldn't sleep last night.

\section{Form used}

a. A dog next door kept me awake.

b. This dog next door kept me awake.

c. The dog next door kept me awake.

d. That dog next door kept me awake.

e. This dog/that/this kept me awake.

f. It kept me awake.
Signaled restrictions

-- (at least) type identifiable

-- (at least) referential: associate a representation by the time sentence is processed

-- (at least) uniquely identifiable: associate a unique representation by time NP is processed

-- (at least) familiar: in memory

-- (at least) activated: in working memory

-- in-focus: center of attention

The statuses are in a unidirectional entailment relation. If something is in focus, it is necessarily activated; if it is activated, it is necessarily familiar; and so on. The theory thus correctly predicts that a given cognitive status can be appropriately coded by a form which explicitly signals that status, but also, in general, by forms whose meanings are entailed by that status. In (9), for example, the phrase these systems explicitly signals that the referent is activated, since this is part of the meaning of the proximal demonstrative determiner this/these in English.

(9) These incredibly small magnetic bubbles are the vanguard of a new generation of ultradense memory storage systems. These systems are extremely rugged...

[Gordon Graff. Better bubbles. Popular Science 232(2):68 (1988)]

The determiner these in these systems is appropriate since the intended referent was just introduced in the preceding sentence and therefore could be expected to be activated for the addressee. But since anything activated is also familiar, uniquely identifiable, referential and type identifiable, other forms would have been appropriate here as well, including those systems, which requires familiarity, the systems, which requires the ability to associate a

3 As a practical matter for the linguistic theorist seeking to discover the form-status correlations for a language, it is essential to determine the cognitive status of an entity on a particular occasion of reference independently of the linguistic form used by the speaker or writer on that occasion. This can be done by examining prior mention of the entity in the discourse, the environmental salience of the entity on the occasion of reference, the descriptive content of the nominal form used on the occasion of reference, and other clues to the cognitive status assumed for the entity by the spcaker (or writer) on the part of the addressee. 
unique representation, or ultradense memory storage systems, which requires only the ability to identify the type.

The use of less restrictive forms has limits, however. The indefinite article is rarely used if the status is higher than referential, and typically implicates non-familiarity. Most in-focus referents are not coded with demonstratives, even though they could be; and demonstratives often implicate a focus shift. Such facts follow from interaction of the Givenness Hierarchy with general pragmatic principles involved in language production and understanding (see Grice 1975, Sperber and Wilson 1986/95). The implicational nature of the GH gives rise to 'scalar implicatures', in the sense of Horn (1972), which further restrict the distribution and interpretation of referring forms (see Gundel, et al 1993, Gundel and Mulkern 1998).

With this background, Gundel, Hedberg and Zacharski propose that the possibility of reference with personal pronouns versus demonstratives depends on the cognitive status of the referent. While both types of pronouns restrict possible referents to those that are activated (in working memory), personal pronouns also require the more restrictive status in focus, that is, their referents must be the current center of attention. This is illustrated in (10)-(11) below, from Gundel et al (1993).

(10) a. My neighbor's bull mastiff bit a girl on a bike.

It's the same dog that bit Mary Ben last summer.

b. Sam found an abandoned dog. It had a broken leg.

(11) Sears delivered new siding to my new neighbors with the bull mastiff.

\#It's the same dog that bit Mary Ben last summer.

That's the same dog that bit Mary Ben last summer.

In (10), an entity introduced prominently in the first sentence is rendered in focus, and then referred to by a personal pronoun in the second. In (11), an entity introduced more peripherally in the first sentence is made activated, but not in-focus, and can be referred to more felicitously by a demonstrative than a personal pronoun in the second.

This permits an explanation of the facts in section 1 in terms of the Givenness Hierarchy. For example, in (2), at the conclusion of A's utterance, the act of destroying the leaf collection can be assumed to be activated, since it was just introduced in the preceding sentence, but not in focus; the focus of attention after the utterance is processed is on the referents of the major arguments in (2A), specifically, John and the leaf collection. Similarly, in (5), the complex situation consisting of potential drawbacks to human cloning is rendered activated by the first paragraph, but we can assume that it is not rendered in focus given the higher salience conferred by this passage on cloned humans, rates of cancer, and other referents of main clause arguments. Accounts of other examples in section 1 proceed along similar lines.

In the following section, we examine factors that contribute to bringing an entity into focus, including the role that information structure plays in determining the cognitive statuses of referents introduced by clauses and thus the nominal forms which can be used to refer to these entities. 


\section{What brings an entity into focus of attention?}

\subsection{Syntactic structure}

The framework outlined above makes predictions about the appropriateness of different pronominal forms depending on whether or not the intended referent can be assumed to be in focus for the addressee. Although the theory itself does not predict what brings an entity into focus, Gundel et al (1993:279) suggest that "the entities in focus at a given point in the discourse will be that partially-ordered subset of activated entities which are likely to be continued as topics of subsequent utterances." Membership in this set is partly, though not wholly, determined by syntactic structure. For example, subjects and direct objects of matrix sentences are more likely to bring an entity into focus than elements in subordinate clauses and prepositional phrases. For similar reasons, the focus of attention at the end of an utterance is more likely to be on the thematic arguments of the verb of a clause within the utterance (including the main clause), than on the proposition, fact, or situation expressed by that clause (cf. the Centering Algorithms of Grosz, Joshi and Weinstein 1983, 1995).

A fact or proposition introduced by an NP within a clause is thus more likely to be brought into focus than one which is introduced by the whole clause. Compare (12) and (13) with the examples in (3) and (4) above, for example.

(12) a. At that moment, Maria brought up another fact. It sent shivers down my spine.

b. Alex then introduced a new proposition. But it was immediately poohpoohed.

(13) Last November, Bailey and Daniel Halperin of the University of California San Francisco wrote an article for The Lancet in which they pointed to evidence that circumcision protects against HIV, and accused public health agencies of disregarding it. [New Scientist, July 8, 2000: 18]

A possible reason for why nominal forms are more likely to bring an entity into focus is that they are not higher order expressions. The difference in semantic type determines different referential behavior, possibly correlated with different criteria of individuation. Hegarty (2001) discusses this connection, proposing that the denotation domains of nominal expressions such as those in (12) are unordered sets, and that elements of unordered sets are conceptualized as fully individuated, discrete objects, akin to concrete objects. Like concrete objects, they can be rendered immediately in focus upon their introduction into a discourse, depending, as in (10)-(11), on whether they are introduced in a sufficiently central syntactic position within the introducing sentence.

\subsection{Less overt factors}

Conditions which appear to boost the salience of entities also include less overt factors such as presuppositions and prior beliefs, and even inquisitive looks, all of which can cause an 
entity to be "reprocessed", and thus brought into focus, even when it is overtly mentioned only once (see Borthen et al 1997 and Gundel et al 1999).

In (14), a baseline case for comparison, the speaker, upon clausally introducing the fact that linguists earn less than computer scientists, can assume that this fact is rendered activated, but not in-focus, for the hearer, leading to a preference for that over $i t$ in the follow-up reference to this fact.

(14) a. I hear linguists earn less than computer scientists, and that's terrible.

b. ??I hear linguists earn less than computer scientists, and it's terrible.

In (15), in contrast, the follow-up reference is made by another speaker, which results in somewhat more complicated inferences regarding the cognitive status of the fact at issue.

Speaker A:

Speaker B:
I just read that linguists earn less than computer scientists.

(i.) That's terrible! (ii.) It's terrible!

At the completion of A's utterance, B can assume that the fact that linguists earn less than computer scientists is at least activated for $A$. In response $B(i), B$ signals the assumption that this fact has been activated, but possibly not brought into focus by A's utterance, thereby inviting $\mathrm{A}$ to infer that the fact is news to $\mathrm{B}$. In response $\mathrm{B}(\mathrm{ii}), \mathrm{B}$ signals the assumption that the fact is in focus for $\mathrm{A}$, or ought to be, consistent with it being accepted background information for discourse in the relevant social circle; this invites A to infer that B already knew the fact.

In (16) below, the proposition that B has a dental appointment is clausally introduced by A's utterance. This, by itself, suffices to activate the proposition, but not to bring it into focus, accounting for why the response (16)B' sounds unnatural.

A: You have a dental appointment at noon.
B: That's true.
B': ??It's true.
B": It's true, then.

But (16)B" is noticeably more acceptable than (16)B'. Following Gundel, Borthen and Fretheim (1999), we suggest an explanation of this fact, drawing on a relevance-theoretic approach to the pragmatics of language understanding (Sperber and Wilson 1986/95). then in B" functions as an interpretive particle which conveys the meaning that the content of the sentence it is appended to follows by way of inference from something the addressee just said. The response by B in (16)B" means essentially, "Given A's assertion that I have a dental appointment at noon, then I can take it as confirmed that I have a dental appointment at noon." The only way B's utterance can yield contextual effects for A is if A's utterance confirmed the truth of a proposition that $\mathrm{B}$ had been questioning, and $\mathrm{B}$ knows that $\mathrm{A}$ is aware of this. Thus, the fact that $B$ had a dental appointment at 3 was not activated for the first time by $A$; rather, A's utterance brought into focus a fact that was already mutually manifest to both A and B beforehand, thereby licensing the use of it in B".

Salience can also be boosted non-linguistically. For example, the exchange in (17) below is fully natural if A gives B a skeptical look during the indicated pause. 
(17) A: Why didn't you come to the rehearsal yesterday?

B: I thought I told you. I had to help Peter move. (Pause) It's true!

The skeptical look communicates A's skepticism about the truth of the proposition just expressed by $B$, thus causing the proposition that $B$ has to help Peter move to be reprocessed (by both $\mathrm{A}$ and $\mathrm{B}$ ) and assuring that it is mutually in focus, making it accessible to reference with it.

Salience of an entity in the environment also suffices for pronominal reference with it. If $\mathrm{A}$ and $\mathrm{B}$ are in a room together with a baby who suddenly begins to walk, $\mathrm{A}$ can produce the utterance in (18), or, if A sees B watching the baby walk, the utterance in (19).

(18) Will you look at that! The baby's walking. (Jackendoff 2001)

(19) Isn't it great? [it = the fact that the baby is walking]

\subsection{The referential behavior of different types of clausally introduced referents}

Another factor which seems to have an effect on whether or not a clausally introduced entity is brought into focus is the degree of world immanence of the entity and, correlatively, its manner and degree of individuation. Asher (1993) suggests that there is a spectrum of world immanence. Events and states, which have causal, spatial and temporal properties, have high world immanence; "purely abstract objects" such as propositions and thoughts have very low world immanence, and their individuation principles depend more on the means we use to describe them than on independent properties of objects in the world. Facts and situations are somewhere in between. Interestingly, this distinction appears to correlate with the accessibility to reference with it versus this or that when the entities in question are introduced by clausal constituents. Events, whose individuation properties are largely independent of the means we use to describe them, have referential properties similar to those of concrete objects and other referents denoted by nominal constituents of clauses, as seen in (20), where either it or a demonstrative this/that can refer to the event described in the first clause. ${ }^{4}$

(20) a. John broke a priceless vase. That happened at noon. [that $=$ the event]

b. John broke a priceless vase. It happened at noon. [it $=$ the event]

Such facts are explained if we assume that the individuating properties that events share with referents of nominal constituents make it more likely that they will be brought into focus immediately subsequent to their introduction with a full clause. The addressee, in processing the first sentence in (20), posits a relation 'break' between John and a vase, and this relation involves an event of John breaking the vase. In the terms of Discourse Representation Theory, with an underlying event semantics for active verbs, the introduction of break' $(u, v, e)$, into a DRS, for discourse entities $u, v$ satisfying $\operatorname{John}(u)$ and $\operatorname{vase}(v)$, requires a discourse entity $e$ for the event in which John broke the vase.

\footnotetext{
4 Since that merely requires activation of its referent, and anything in focus is also activated, in focus entities can be referenced with either that or $i t$.
} 
Situations are somewhat less accessible to reference with $i t$, as seen in (21).

(21) a. John broke a priceless vase. That/this was intolerable to the embassy.

b. John broke a priceless vase. ??It was intolerable to the embassy.

The predicate intolerable in (21) precludes an interpretation on which the demonstrative pronoun refers to the event of John breaking the vase, since an event is unchangeable once it has occurred, and thus cannot fail to be tolerated. The situation of John breaking the vase, in contrast, includes its ramifications, and those at least, are subject to amelioration or change, making it sensible to say that the situation is intolerable to the embassy, which will therefore require a change in the situation (realized as a change in the consequences or ramifications) without any change in the associated event in which the vase was broken. The inclusion, or potential inclusion, of ramifications as part of a situation, but not as part of an event, is plausibly what makes a situation not clearly delimited in spatiotemporal extent, and therefore less fully or clearly individuated upon introduction than an event.

Thus, situations, which are less world immanent than events, and less susceptible to individuation by spatiotemporal extent, are also less likely to be brought into focus upon first introduction with a full clause. The examples in (1) and (5) bear this out. Example (3) shows that facts pattern with situations, and not with events, in their availability for subsequent pronominal reference. Finally, as examples (4) and (6) show, clausally introduced propositions, which lie at the low end of the world immanence spectrum, are typically not available for subsequent pronominal reference with it. The proposition expressed by an utterance is activated by that utterance but is typically not brought into focus.

In order for an utterance to bring some entity into focus it is necessary, (though not sufficient) that the entity be directly expressed as part of the propositional content of the utterance. This explains, at least partly, the contrast between events on the one hand, and situations, facts and propositions on the other. Speech acts (i.e. acts performed by an utterance, which are not part of the propositional content) are thus never brought into focus, and consequently inaccessible to subsequent reference with 'it'. This is illustrated in (22) and (23).

(22) Thorne: So you fired her?

Eric: We're going to do a lot more than just fire her, Thorne.

Thorne: What does that mean? (from the TV soap opera "The Bold and the Beautiful")

\#What does it mean?

(23) A. John snores.

B. That's rude.

B'. It's rude.

In (22), the demonstrative that is interpreted as referring to Eric's statement 'We're going to do more than just fire her'. This interpretation is impossible if that is replaced with $i t$, and 
the resulting sentence is thus unacceptable in this context. In (23), the demonstrative pronoun that in (B) is ambiguous between an interpretation where it refers to the act of John snoring and an interpretation where it refers to A's illocutionary act of informing $B$ of this fact. By contrast , (23B') can only have the former interpretation.

\section{The role of information structure}

The cognitive status, and therefore the accessibility to pronominal reference, of a clausally introduced entity is partly constrained by the information structure of the utterance in which it is introduced into a discourse. ${ }^{5}$ In particular, information structure yields some striking effects, but also a surprising asymmetry, when higher order entities are introduced by (or within) clausal complements.

Entities introduced by clausal complements to bridge verbs, such as think, believe, and say, exhibit the familiar pattern of being rendered activated, but not in-focus, through mention by a clause. This is shown by the naturally occurring example in (24) below, as well as by the constructed data in (25), tested on a small survey of English speakers. ${ }^{6}$

(24) Ising reportedly believed that his negative results would hold in higher dimensions as well.

In this conjecture he was wrong. (American Scientist 88:385)

In this/ \#it, he was wrong.

(25) A: Alex believes [F that the company destroyed the FILE].

B: That's false; the file has been submitted to the district judge.

B': \#It's false; the file has been submitted to the district judge.

When (25A) is used with the focus-structure shown, to introduce the proposition that the company destroyed the file, the response by $\mathrm{B}$ using that is much more felicitous than the response with it. However, it and that are equally good when the complement clause is in the ground (theme; topic) of A's utterance, as in (26A).

(26) A: Alex [F INSISTS/BELIEVES] that the company destroyed the file.

B: But that's/it's false; the file has been submitted to the district judge.

5 By information structure, we mean a bifurcation of material in an utterance into what has been called focus versus ground, comment versus topic, or rheme versus theme. This notion is not to be identified with contrastive focus or with the more general distinction between new versus old information. Information structural focus is also distinct from the cognitive status 'in focus'. See Vallduví (1990) and Gundel (1999a) for more detailed discussion of related terminological and conceptual issues. We will indicate information structural focus by the subscript ' $F$ '.

6 The use of $i t$ in (24) would be just as infelicitous if the PP were not preposed. Thus, the infelicity of it in (24) cannot be attributed to its incompatibility with the secondary focal stress it bears in this position. 
Since an entity associated with the ground (theme; topic) is already at least familiar to the addressee prior to the utterance (see Gundel 1988 inter alia), its mention within the utterance suffices to bring it into the focus of attention, if it does not already have that status.

In (24)-(26), relational givenness/newness and referential givenness/newness (in the sense of Gundel 1988, 1999a,b) are coextensive. For example, the information structural focus in (25) represents a proposition that is not only new in relation to the topic (what Alex believes), but also referentially new to the hearer; and the clausal complement in the ground of (26) expresses a proposition which is not only given in relation to the informational structural focus, but also referentially given in the sense of being already at least familiar and probably also activated. But material in the informational focus doesn't have to be referentially new (see Gundel 1980, 1999a,b, Vallduví 1990, Lambrecht 1994). So when we have a bridge verb complement which is an information structural focus, but is already activated in the discourse, which factor wins out? Is an entity expressed by such a complement rendered in focus or does it remain merely activated? Is it accessible to reference with $i$, or only with that? Consider (27B2).

(27) Al: I believe that the company destroyed the file, but not everybody does.

B1: What does Alex believe?

A2: Alex believes [F that the company destroyed the file].

B2: But it's/that's false; the file has been submitted to the district judge.

(27B2) suggests that it is referential givenness (i.e. cognitive status of a discourse entity), and not relational givenness (i.e. topic-focus structure), that determines whether the complement of a bridge verb will be brought into focus.

But now flip the problem around. Content in the topic/ground of an utterance does not always have a high degree of referential givenness. It's cognitive status may be merely familiar, but not necessarily activated. So when we have a bridge verb complement which is ground material, but new to the discourse, which factor wins out? Is an entity introduced by such a complement rendered in-focus, because it is in the ground, or merely activated, because it is new to the discourse? Is it accessible to reference with it, or only with that? Consider (28) [secondary stress on murdered]:
a. Alex is hopeless.
b. He [F INSISTS] that Tom was murdered, for example,
c. -- even though there's not a shred of evidence for that.
-- even though there's not a shred of evidence for it.

Use of $i t$ is as felicitous as that in (28c). The information structure of (28b) forces the addressee to accept the content of the complement clause as already familiar, so that (28b) renders it in focus, making it available to reference using it. Thus, presentation of a clausally introduced entity in the ground of an utterance is another way to promote salience, and bring the entity into focus, even if it is, in fact, new to the discourse. 
With bridge verb complements, we thus appear to have an asymmetric situation: bifurcation into focus/ground has no effect on the cognitive status of an entity introduced within the information structural focus. ${ }^{7}$ But it can have an effect when an entity is mentioned (even introduced) within ground material, because mention within the ground necessarily signals a higher cognitive status for the entity. This conclusion is preliminary, however, in that the judgments are subtle, and naturally occurring data that would bear directly on the issue is sparse.

\section{Lexical structure versus information structure}

When the bridge verb in (25)-(28) is replaced with a factive verb, demonstrative and personal pronouns can both be used to immediately refer to the entity expressed by the complement clause, regardless of the information structure of A's utterance. (Constructed data surveyed on a sample of English speakers.)

(29) A. Alex verified that the company destroyed the file.

B. That's false; the file has been submitted to the district judge.

B'. It's false; the file has been submitted to the district judge.

Thus, the contrast in (25) between subsequent reference with it versus that is not exhibited in (29), and the contrast between (25) and (26), exhibiting a partial effect of information structure on cognitive status, is also absent. The lexical semantics of the factive verb enforces the condition that the entity expressed by the complement clause be already familiar (or at least capable of being accommodated as familiar) to the addressee, so that its further mention in A's utterance renders this entity in focus.

In order to understand this fully, it is useful to note that this pattern is not confined to complements of factive verbs. It is also obtained in complements to certain non-factive (and non-bridge) verbs, including agree, emphasize, deny, and doubt, and in complements to the non-factive adjectival predicate be certain. ${ }^{8}$

(30) a. Alex and Susan agree that the company destroyed the file. I'm surprised that they believe it.

b. Alex and Susan agree that the company destroyed the file. I'm surprised that they believe that.

(31) A: Alex is certain that the company destroyed the file.

B: That's false: the file has been submitted to the district judge.

B': It's false: the file has been submitted to the district judge.

7 Gundel (1999a) makes a similar observation, concluding that mention within the information structural focus (her 'semantic focus') doesn't necessarily bring an entity into focus of attention.

8 Cattell (1978) noticed that these non-factives pattern with factives in wh-extraction from their complements. See also Melvold (1991), Hegarty (1992), and Schulz (1999) for discussion of this class of predicates. 
As with factive predicates, the pattern in (30)-(31) is one in which it is at least as felicitous as that in referring to the content of the complement clause, and, in some cases, more so.

The predicates in (30)-(31) are not factive (in the sense made clear by Kiparsky and Kiparsky 1971) since they don't commit the speaker of the ascription in which they occur to the truth of their complement clauses. However, they share with factives a slightly more subtle semantic property: they are felicitous when the proposition, fact, or situation expressed by the complement clause is not an entirely new entity, but rather, an entity already accepted as given or familiar in the discourse. The ascriptions with agree and certain in (30)-(31), as well as the factive ascription in (29), would be odd if used to introduce into the discourse the fact or proposition that the company destroyed the file. Using a situation variable in the semantics, in the context of Discourse Representation Theory (Kamp and Ryle 1993), the interpretation of the factive ascription in (29) can be expressed by the Discourse Representation Structure (DRS) shown in (32) below. ${ }^{9}$ The ascriptions with agree and certain in (30)-(31), though non-factive, would have identical DRS's, with trivial substitution of the verb denotations.

\begin{tabular}{|l|}
\hline$u, v, z, s$ \\
\hline Alex $(u)$ \\
Company $(v)$ \\
File $(z)$ \\
destroy $(v, z, s)\left(w_{o}\right)$ \\
verify $(u, \lambda w[$ destroy $(v, z, s)(w)])$ \\
\hline
\end{tabular}

In contrast, a belief ascription such as that in (25A), using a bridge verb, is interpreted semantically as just a relation between Alex and the proposition expressed by the complement clause. A DRS for (25A) is presented in (33).

\begin{tabular}{|l|}
\hline$u, v, z, s$ \\
\hline Alex $(u)$ \\
Company $(v)$ \\
File $(z)$ \\
believe $(u, \lambda w[\exists s[$ destroy $(v, z, s)(w)]])$ \\
\hline
\end{tabular}

Of course, the ascription made by $\mathrm{A}$ in (25) could express a proposition which is already familiar to the hearer. The property distinguishing bridge verbs from the factive and other predicates discussed here is not that the content of the bridge verb complement must be

9 Subordinate DRSs are abbreviated as formulas here to save space. For semantic representations using a situation variable, see Ginzburg (1995ab), and, for similar structures with an event variable, Higginbotham (1985, 1989). Schultz (1999) presents a proposal very similar in spirit to that represented in (32), but implemented quite differently in the context of Heim's (1982) File Card Semantics. 
unfamiliar, but only that it can be. Bridge verbs, unlike other predicates discussed here, do not assume the familiarity of the content of the complement.

Interrogatives pattern with factive complements with regard to the status of abstract entities mentioned by or within them. Naturally occurring data are shown in (34) and (35). ${ }^{10}$

(34) One common attribute of a scientist is an unusually acute sense of numbers and their implications. I think it was Bertrand Russell who once observed that mankind would rather commit suicide than learn arithmetic. In other words, the meaning and implications of some numbers are often lost on most people - even when those numbers bring a very important message. George Bernard Shaw stated that one distinguishing characteristic of an educated person is that he or she can be emotionally moved by statistics.

A sense of numbers - why do I dwell on this observation? Perhaps it's because we who come from a background of engineering, mathematics and science tend to convey concepts and findings in terms of numbers; yet many for whom our messages are intended find our communications (full of numbers as they are) unappetizing, boring, unconvincing and a bit standoffish. (American Scientist $88: 378)$

(35) Where and for how long saguaro, cardon, and organ pipe lived together before moving into the Sonoran Desert is currently unknown. Thus, we do not know where these species evolved the phenological differences that reduce their joint reliance for pollination on a single species of nectar-feeding bat.

One hint about this, however, comes from geographic variation in the timing of peak flowering in organ pipe. [This can be felicitously replaced with it here, without affecting interpretation:]

One hint about it, however, comes from geographic variation in the timing of peak flowering in organ pipe. [ $i t=$ where these species evolved the differences that reduce their joint reliance for pollination on a single species of nectar-feedingbat.]

Constructed data has been tested on a small survey of English speakers, with the results shown in (36)-(37).

(36) A: Alex wonders whether the company destroyed the file.

B: It's not likely. The file contained no incriminating information.

B: That's not likely. The file contained no incriminating information. [it/that $=$ that the company destroyed the file]

(37) a. Alex wonders who destroyed the file; it has impeded the investigation.

b. Alex wonders who destroyed the file; that has impeded the investigation.

[it/that $=$ that someone destroyed the file]

10 Also, note that the first paragraph of (35) could felicitously be followed by $I t$ is a mystery, with it interpreted as specified at the end of the example. 
The possibility of immediate subsequent reference with a personal pronoun in (36)-(37) follows from the presuppositional nature of questions. To simplify, within DRT, the wonder-ascription in (36A) should be represented with a DRS of the form shown in (38), where $\varphi$ is an appropriate relation between Alex and the proposition $p$ specified on the penultimate line of the DRS. ${ }^{\prime \prime}$

\begin{tabular}{|l|}
\hline$u, v, z, s, p$ \\
\hline Alex $(u)$ \\
Company $(v)$ \\
File $(z)$ \\
$p(w)=\lambda w \exists s[\operatorname{destroy}(v, z, s)(w)]$ \\
$\varphi$ \\
\hline
\end{tabular}

Interpreted as in (38), the wonder-ascription in (36A) is a question about the proposition that the company destroyed the file. This should be the form of any semantic account of the wonder-ascription which captures the presuppositionality of the embedded question: the proposition that the company destroyed the file must be an established discourse entity prior to the utterance of (36A), or it must be accommodated in the sense of Heim (1982). The assertive content of (36A) should be captured in the last line of the DRS, $\varphi$. On one realization of $\varphi$, given in Hegarty (2001), (36A) asserts that Alex is in the state of wonder with respect to the proposition that $p$ holds of the actual world, $w_{0}$.

The embedded interrogative in (37) is also presuppositional: it pertains to the property that holds (across worlds) of those who destroyed the file, and asserts of it that Alex is in the relation of wonder to this property instantiated on the actual world. The property must be either established prior to the utterance of (37), or accommodated on the occasion of utterance. A DRS expressing the semantic interpretation of the wonder-ascription in (37) should therefore have the form shown in (39).

\begin{tabular}{|l|}
\hline$u, v, z, s, p$ \\
\hline Alex $(u)$ \\
Company $(v)$ \\
File $(z)$ \\
$P(w)=\lambda w \lambda x \exists s[$ destroy $(x, z, s)(w)]$ \\
$\varphi$ \\
\hline
\end{tabular}

A simple representation of the assertion of the wonder-ascription in (37) is $\varphi=$ wonder $(a$, $\left.P\left(w_{o}\right)\right)$.

11 To unsimplify, questions are, in fact, constrained not only by the formal semantic condition captured here, but by rich contextual conditions on what would count as a suitable answer to a question in a given context. See Ginzburg (1995ab) and Asher and Lascarides (1998). The important point, for present purposes, is that these accounts would incorporate, and add to, the presuppositional condition given here. The proposals sketched here would therefore be a part of an account given according to these richer theories of the interpretation of questions. 
The content of $p$, specified in the penuitimate line of the DRS in (38), is thus mentioned again within the condition $\varphi$. The penultimate line in (38) thus enforces double processing of the proposition that the company destroyed the file, rendering it in-focus at completion of the wonder-ascription in (36A). The penultimate line in (39) does the same for the property "destroy the file" at completion of the wonder-ascription in (37). Thus the penultimate line expressing the presuppositionality of questions in (38) and (39) is analogous to the effect of the penultimate line of the DRS for factive (and similar) ascriptions, in (32) above.

Thus, the presuppositionality involved in the lexical structure of a factive (or related) predicate, and the semantic presuppositionality of embedded questions, are additional factors which can bring an entity into focus. In these cases, information structure has no bearing on the cognitive status of the clausally introduced entity.

\section{Conclusion}

In this paper, we addressed the fact that clausally introduced entities, immediately subsequent to their introduction into a discourse, are typically accessible to reference with a demonstrative pronoun, but not with the personal pronoun $i t$. We found that this fact can be explained on the basis of the observation that such entities are typically activated, but not brought into focus, upon their introduction to a discourse. However, clausally introduced entities are, in fact, sometimes referenced with it immediately subsequent to their introduction. An examination of the discourse environments in which this is possible provides important insights into the various syntactic, semantic, and pragmatic factors that can boost the salience of an entity and bring it into focus.

We've shown that information structure, in the sense of a focus/ground bifurcation, is one such factor when an entity is mentioned with a bridge verb complement, but only in a way which is asymmetric, depending on whether the entity is mentioned within focal or non-focal material. When the complement is focal, there is no effect: the cognitive status of an entity expressed by a focal complement depends entirely on the referential givenness/newness (i.e. the cognitive status) of the entity. But when the complement is part of the ground (topic/theme), the entity is brought into focus.

In factive complements and embedded questions, the lexical nature of the embedding predicate and the semantic nature of the construction require an entity mentioned with the subordinate clause to be treated as referentially given independently of the informationstructure of the utterance.

\section{References}

Asher, Nicholas. (1993). Reference to Abstract Objects in Discourse. Dordrecht: Kluwer.

Asher, Nicholas, and Alex Lascarides. (1998). Questions in dialogue. Linguistics and Philosophy 21:237-309.

Borthen, Kaja, Thorstein Fretheim and Jeanette. K. Gundel. (1997). What brings a higher-order entity into focus of attention? In R. Mitkov and B. Boguraev (eds.) Operational factors in practical, robust anaphora resolution, pp.88-93.

Cattell, Ray. (1978). On the source of interrogative adverbs. Language 54: 61-77. 
Ginzburg, Jonathan. (1995). Interrogatives I. Linguistics and Philosophy 18:459-527.

Ginzburg, Jonathan. (1995). Interrogatives II. Linguistics and Philosophy 18:567-609.

Grice, H. P. (1975). Logic and Conversation. In P. Cole and J.L. Morgan, eds., Syntax and Semantics 3. Speech Acts. 41-58.

Grosz, Barbara J., Aravind K. Joshi, and Scott Weinstein. (1983). Providing a unified account of definite noun phrases in discourse. In Proceedings for the $21^{s t}$ Annual Meeting of the Association for Computational Linguistics, Cambridge, Mass., pp.44-50.

Grosz, Barbara J., Aravind K. Joshi, and Scott Weinstein. (1995). Towards a computational theory of discourse interpretation. Computational Linguistics 21:203-25.

Gundel, Jeanette K. (1980). Zero NP-anaphora in Russian: a case of topic-prominence. Proceedings from the Parasession on Anaphora. Chicago Linguistic Society, 139-146.

Gundel, Jeanette K. (1988). Universals of topic-comment structure. In M. Hammond et al, eds. Studies in Syntactic Typology. Amsterdam: John Benjamins. 209-239.

Gundel, Jeanette K. (1999a). On three kinds of focus. In P. Bosch and R. van der Sandt, eds. Focus. Linguistic, Cognitive and Computational Perspectives. Cambridge University Press.

Gundel, Jeanette K. (1999b). Topic, focus and the grammar pragmatics interface. In J. Alexander, N. Han and M. Minnick, eds. Proceedings of the 23rd Annual Penn Linguistics Colloquium. Penn Working Papers in Linguistics, vol. 6.1.

Gundel, Jeanette K., Nancy Hedberg and Ron Zacharski. (1993). Cognitive status and the form of referring expressions in discourse. Language 69:274-307.

Gundel, Jeanette K., Kaja Borthen and Thorstein Fretheim. (1999). The role of context in pronominal reference to higher order entities in English and Norwegian. In P. Bouquet et al, eds. Modeling and using context. Lecture notes in Artifical Intelligence. Berlin: Springer Verlag.

Gundel, Jeanette K. and Ann Mulkern. (1998). Quantity implicatures in reference understanding. Pragmatics and cognition 6: Special issue on the concept of reference in the cognitive sciences, 21-45.

Heim, Irene. (1982). The Semantics of Definite and Indefinite Noun Phrases. Doctoral dissertation, University of Massachusetts, Amherst.

Hegarty, Michael. (1992). Adjunct extraction without traces. In Dawn Bates, ed., Proceedings of the Tenth West Coast Conference on Formal Linguistics. Stanford: CSLI, pp.209-223.

Hegarty, Michael. (2001). Reference to abstract entities within clausal complements. Proceedings of the Annual Meeting of the Berkeley Linguistics Society.

Higginbotham, James. (1985). On semantics. Linguistic Inquiry 16:547-593.

Higginbotham, James. (1989). Elucidations of meaning. Linguistics and Philosophy 12:465-517.

Horn, Lawrence R. (1972). On the semantic properties of logical operators in English. UCLA dissertation.

Jackendoff. Ray. (2001). Reference and truth. Plenary Talk. Annual Meeting of the Linguistic Society of America. Washington, D.C.

Kamp, Hans, and Uwe Reyle. (1993). From Discourse to Logic. Dordrecht: Kluwer Academic Publishers.

Kiparsky, Paul and Carol Kiparsky. (1971). Fact. In D. Steinberg and L. Jacobovits, (eds.) Semantics. Cambridge: Cambridge University Press, pp. 345-369.

Lambrecht, Knut. (1994). Information structure and sentence form: topic, focus, and the mental representations of discourse referents. Cambridge: Cambridge University Press.

Melvold, Janis. (1991). Factivity and definiteness. In Lisa Cheng and Hamida Demirdash, eds., More Papers on WH-Movement. MIT Working Papers in Linguistics, vol.15. Cambridge, MA, pp.97-117.

Schulz, Petra. (1999). Getting the Facts: Finite Complements, Factive Verbs and their Acquisition. Doctoral dissertation, Tübingen University.

Sperber, Dan and Deirdre Wilson. (1986/95). Relevance: Communication and cognition. London: Blackwell. 2nd Edition.

Vallduví, Enric. (1990). The Informational Component. Doctoral dissertation, University of Pennsylvania, Philadelphia.

Webber, Bonnie Lynn. (1988). Discourse deixis and discourse processing. Technical report, University of Pennsylvania.

Webber, Bonnie Lynn. (1991). Structure and Ostension in the Interpretation of Discourse Deixis. Language and Cognitive Processes 6.2:107-135. 


\title{
Scrambling and Reference in German
}

\author{
Jürgen Lenerz \\ University of Cologne \\ juergen.lenerz@uni-koeln.de
}

\begin{abstract}
Although the linear order of arguments (and adverbials) in German is relatively free, it underlies certain restrictions; these don't apply to the so-called unmarked order for arguments (Lenerz 1977) and adverbials (Frey/Pittner 1998). It is a common assumption to take the unmarked order as basic and derive all other orders from it by scrambling, whatever its specific characteristics may be (cf., amongst others, Haider/Rosengren 1998). The observable restrictions obtaining for some linear ordering may then be considered as constraints on a movement operation (scrambling). Some well known restrictions are given in (1), exemplified by the linear order of indirect (IO) and direct object (DO). In the examples (2) - (4), the focussed NP is the questioned argument, e.g. $\mathrm{Q}: \mathrm{IO}$ in (2):
\end{abstract}

(1) a. $\quad[ \pm$ def $\mathrm{IO}]>[ \pm$ def $\mathrm{DO}]$ : "unmarked order", regardless of focus position (cf. (2a), (3a), (4a)).

b. $\quad[+\operatorname{def} \mathrm{DO}]>[\mathrm{IO}]_{\mathrm{F}}$ : scrambling of $[+$ def, $-\mathrm{F}]$ is ok (cf. $\left.(2 \mathrm{~b})\right)$.

c. $\quad *[ \pm \text { def } D O]_{\mathrm{F}}>\mathrm{IO}=$ Don't scramble focus ! (cf. (3))

d. $\quad *[-\operatorname{def} \mathrm{DO}]>[\mathrm{IO}]_{\mathrm{F}}=$ Don't scramble (existential) indefinites! (cf. (4))

(2) Wem hast du das Buch gegeben?

Q : IO

'Whom did you give the book?'

a. Ich habe [dem/einem StuDENten $]_{F}$ das /ein Buch gegeben.

$[ \pm \text { def. } I O]_{F}>[ \pm$ def. DO $]$

I have the / a student the /a bookgiven

("unmarked order")

b. Ich habe das Buch [dem/einem StuDENten $]_{F}$ gegeben

I have the book the / a student given

$[+$ def. DO $]>[ \pm \text { def. IO }]_{\mathrm{F}}$ (scrambled $[+\operatorname{def} \mathrm{DO},-\mathrm{F}]$ is o.k.)

'I gave the book to the student.'

(3) Was hast du dem Studenten gegeben?

Q : DO

'What did you give to the student?'

a. Ich habe dem Studenten [das BUCH$]_{\mathrm{F}}$ gegeben.

$I$ have the student the book given ("unmarked order")

b. *?Ich habe $[\text { das BUCH] }]_{\mathrm{F}}$ dem Studenten gegeben.

$*[+ \text { def. } \mathrm{DO}]_{\mathrm{F}}>[+$ def. $\mathrm{IO}]$

I have the book the student given (*scrambled focus)

'I gave the student the book.' 
'Whom did you give a book?'

a. Ich habe [dem/einem StuDENten $]_{F}$ ein Buch gegeben

$$
\text { I have the / a student a book given }
$$

$[ \pm \text { def. } \mathrm{IO}]_{\mathrm{F}}>[$-def. DO $]$

b. $\quad *$ Ich habe ein Buch [dem StuDENten $]_{F}$ gegeben.

("unmarked order")

I have a book the student given

$$
*[\text {-def. DO }]>[+ \text { def. } \mathrm{IO}]_{F}
$$

(*scrambled indefinite NP)

c. $\quad *$ Ich habe ein Buch [einem StuDENten $]_{F}$ gegeben.

$$
\begin{array}{ccccc}
I & \text { have } a \text { book } & a & \text { student } & { }^{*}[\text {-def. } \mathrm{DO}]>[\text {-def } \mathrm{IO}]_{\mathrm{F}} \\
& \left({ }^{*}\right. \text { scrambled indefinite NP) }
\end{array}
$$

'I gave a book to the student.'

As the standard examples in (2)-(4) show, IO > DO is assumed to be the unmarked order for most verbs taking two objects; here, no specific restrictions apply: every distribution of definite or indefinite NP and focus is possible for that order, cf. (2a), (3a), (4a). Scrambling a definite DO to the left of a focussed IO gives a possible order, too, cf. (2b). If, however, the scrambled DO is a focussed NP, it must not be scrambled in front of an IO, cf. (3b). Thus, (1c) "Don't scramble focus!" is a crucial restriction on scrambling in German. It may be accounted for by the interaction of focus placement, focus projection and, possibly, the proper assignment of prosodic features (cf., amongst others, Büring 1997, 2001, von Heusinger 1999). Thus, this restriction may find a plausible functional explanation ensuring the proper interpretation of a sentence wrt background-focus structure and the formal means for its expression, i.e. linear order and prosodic prominence.

There is, however, an additional restriction, for which, to my knowledge, so far no explanation has been proposed. As (4b), (4c) show, an indefinite DO should not be scrambled across an IO, even if the condition (1c) on focus-scrambling is not violated. Examples (4b), (4c) suggest that scrambling of an indefinite DO is not possible in general. As (5a), however, shows, the scrambled DO einen obszönen Witz ("an obscene joke') may be scrambled under certain conditions:

Wem erzählt Peter einen obszönen Witz? „Whom does Peter tell an obscene joke?"

a. Peter erzählt einen obszönen Witz immer einem Schulfreund. (generic)

Petertells an obscene joke always a-DAT schoolmate

'Peter tells an obscene joke always to a schoolmate.'

As far as is known, in this case the scrambling must be to a position outside the VP, as indicated by the temporal adverbial immer ('always') which is assumed to indicate the left boundary of VP. In this case, the scrambled DO may receive a non-existential, generic reading. Thus, the proper constraint on scrambling is assumed to be (1d) "Don't scramble existential indefinites!". Generic indefinites, however, may be scrambled (provided that the sentence itself allows for a generic interpretation). 
It should be pointed out, however, that this restriction is still too weak: Scrambling across a subject (6a) is still not possible, whereas the (generic) subject itself may be scrambled as in (6b).
a. *weil einen obszönen Witz immer Peter einem Schulfreund erzählt. since an obscene joke always Peter a-DAT schoolmate tells
b. weil obszöne Witze immer an Herrenabenden erzählt werden. since obscene jokes always on boy-nights told become 'Since obscene jokes will always be told on boys' nights.'

Thus, scrambling seems to be also sensitive to the syntactic hierarchy of arguments. Possibly, the restriction as stated above in (1d) is also too strong: In some cases the scrambling of existential indefinites seems to me to be possible, as will be shown below, cf. (14b).

In the following, I will try to present the outlines of a possible explanation for the restriction (1d), based on a proposal governing the proper referential interpretation of indefinite NPs.

Before doing so, however, let me point out some crucial shortcomings of some current proposals.

It has been assumed that syntactic structure shows a bi-partition parallel to the bipartition of a formula of standard predicate logic (cf. Diesing 1990 and much consecutive discussion). A quantified logical formula like

$$
\forall \mathrm{x}(\operatorname{man}(\mathrm{x})) \exists \mathrm{y}(\text { woman }(\mathrm{y}) \wedge \text { love }(\mathrm{x}, \mathrm{y}))(\text { every man loves a woman })
$$

may be split into a restrictive clause defining the domain of the universal quantifier ( $\forall \mathrm{x}$ $($ man $(\mathrm{x})))$ and the so-called nuclear scope $(\exists \mathrm{y}($ woman $(\mathrm{x}) \wedge$ love $(\mathrm{x}, \mathrm{y}))$ ) containing the assertion being made of the individual(s) in the restrictive clause.

$$
\begin{aligned}
& \text { a. } \quad \forall \mathrm{x}(\operatorname{man}(\mathrm{x})) \quad\|\mathrm{I}\| \exists \mathrm{y}(\text { woman }(\mathrm{y}) \wedge \text { love }(\mathrm{x}, \mathrm{y}))(\text { every man loves a } \\
& \text { restrictive clause IIII nuclear scope } \\
& \text { (CP) } \operatorname{IP}[\ldots . .[\text { Sadv IIII } \mathrm{vP}[\ldots .]] \\
& \forall \text {, GEN IIII } \exists
\end{aligned}
$$

So, some authors have assumed that the part of a sentence before the sentence adverbial corresponds to the restrictive clause, the part following the adverbial representing the nuclear scope. The readings in $(8 \mathrm{a}, \mathrm{b})$ are thus assumed to follow from a syntactic bipartition corresponding to the bi-partition of the formula of standard predicate logic.

(8) a. weil ein Feuerwehrmann ${ }_{i}$ natürlich immer [vp $t_{i}$ beREIT $]_{v p}$ ist:

because a fireman naturally always ready is
'because a fireman is of course always ready'


b. weil natürlich immer [vP ein Feuerwehrmann beREIT ]vp ist:

because naturally always a fireman existential reading
'because there is of course always a fireman ready'

Notice, however, that there is no reason why the syntactic structure should correspond to a fairly arbitrary partition of a formula of standard predicate logic as the latter was not devised to reflect syntactic structure at all. Consequently, a proper semantic structure giving us a compositional semantic interpretation of sentences like (8a) or (8b) will deviate from the fairly simple format of (7), as a more detailed representation in categorial grammar would show immediately. Such representations are indeed based on the syntactic structure which is taken to be independent of semantic translations like (7) and exist prior to them.

For this reason, I tried to provide an independent motivation for the syntactic bipartition (Lenerz 2001). I assumed that the part preceding the sentence adverbial (thus: outside the VP) be interpreted as the part of the sentence containing background information (B-part) whereas the VP proper be the part containing the focussed elements (F-part), i.e. the new information being asserted to hold true of the B-part.

$$
\begin{aligned}
& \text { b. (CP) }{ }_{\mathrm{IP}}[\ldots .[\mathrm{Sadv} \quad \mathrm{III} \quad \mathrm{vP}[\ldots .]] \\
& \text { B-part IIII F-Part (background vs. focus) } \\
& b \text {-determined reference III isc-dependent reference } \\
& \text { (isc = immediate sentence constituent) }
\end{aligned}
$$

This provided a first step towards an explanation of the scrambling restriction (1d):

The reference of the elements in the B-part is plausibly established by background information (b-determined reference). Thus, indefinites in the B-part should be interpreted as given or known in their reference, hence as generic. On the other hand, the referential expressions in the F-part represent new information. Their reference is, however, restricted by other referential expressions in the sentence as a whole, i.e. dependent on immediate sentence constituents (isc-dependent reference). Although I think that this proposal was basically on the right track, it has two shortcomings: First, in the light of recent work of Frey (2000) the characterization of the bi-partition into "Bpart" and "F-part" is misguided. Rather, as Frey (2000) points out, the sentence adverbials (or, more precisely, possibly the temporal adverbials) marking the left boundary of the VP proper distinguish between a field containing a (number of) topic phrase(s) and the VP proper containing only the comment (cf. also Rizzi 1997), cf. (12) below.

Second, the restriction of the reference of isc-dependent expressions seems to me far more general than I assumed in Lenerz (2001).

Let us therefore take a closer look at the referential properties of indefinite NPs. Indefinite determiners may be interpreted as choice functions which pick an arbitrary referent out of a "reference set" which is characterized by the noun (cf. von Heusinger 1997). The proper choice of the "reference set" of a given NP itself is dependent on (restricted by) the reference of expressions which c-command the NP in D-structure (X $\leftarrow$ ref.dep. $\leftarrow \mathrm{Y}=\mathrm{Y}$ is referentially dependent on / referentially restricted by $\mathrm{X}$ ); hence the 'unmarked order' of arguments $(\mathrm{SU}<\mathrm{IO}<\mathrm{DO}<\mathrm{V})$ which does not underlie 
any restrictions w.r.t. context / information structure / referential status: SU $\leftarrow$ ref.dep $\leftarrow$ IO $\leftarrow$ ref.dep. $\leftarrow$ DO

So, in (9) the indefinite NP ein Buch does not refer to any arbitrary element of the set of books but is in its reference restricted by at least the c-commanding referential expressions der Professor and dem Studenten. A rough rendering of its interpretation may be given as $(9 \mathrm{~b})$.

(9) a. weil (der) Professor (dem) Studenten gestern ein Buch gegeben hat. since the professor the-DAT student yesterday a-ACC book given has 'Since the professor gave the student a book.'

(9) b. ein Buch $=[1$ an arbitrary element of the set of books which were available yesterday to the professor and the student l]

Here, 'available' is a rather vague term synonymous with what I dubbed dependent or restricted further above.

Similarly, the reference of the indefinite NP einem Studenten in (9c) may be paraphrased as $(9 \mathrm{~d})$.

(9) c. weil der Professor gestern einem Studenten das Buch gegeben hat. since the professor yesterday a-DAT student the-ACC book given has 'Since the professor gave a student the book.'

(9) d. einem Studenten $=[$ I an arbitrary element of the set of students which were available yesterday to the professor I]

The essential idea now is that an indefinite NP looses its referential dependency if it is scrambled. Different versions of this idea come to mind, as W. Frey (p. c.) pointed out to me: In a strong version, a scrambled NP looses its referential dependency altogether. In this view, a scrambled NP has to be interpreted as referring to an arbitrary element of the non-restricted set of elements defined by the noun. A weaker version would hold that a scrambled NP looses only the referential dependency which extends from those referential expressions across which it has been scrambled. I have not been able to decide empirically which version is correct. One observation may be in favor of the weak version: Scrambling across an object NP (10a) seems to result in a weaker deviation than scrambling across an object and a subject $(10 \mathrm{~b})$ :

(10) a. ?*weil der Professor ein Buch dem Studenten gegeben hat. since the professor a-ACC book the-DAT student given has 'since the professor gave a book (to) the student.'

b. *weil ein Buch der Professor dem Studenten gegeben hat. Since a-ACC book the professor the-DAT student given has

Similar grades of ungrammaticality may also be observed with scrambling across adverbials. This is an area requiring some further investigation. It follows, however, from both versions that the scrambling of an indefinite NP results in a loss of its proper referential dependency. Thus, a proper interpretation of the sentence will no longer be possible if the sentence consists of a specific predication made of its subject NP. So, in the strong version of the principle of referential dependency, an interpretation of an ungrammatical sentence like (10b) will be something like (11), certainly a paraphrase of an utterance which does not make any sense. 
(11) * it is true for [ [ any arbitrary book $]$ that a specific professor gave it to a specific student at a specific time.

So far, a concept of the referential dependency of indefinite NPs will enable us to account for the ungrammaticality of scrambled NPs if they are to be interpreted as existential.

In order to account for the generic interpretation of (at least some) scrambled indefinites, we will have to take a closer look at the topological and hierarchical structure of German sentences. As Rizzi (1997), Fry (2000), Frey/Pittner (1998), Meinunger (2000) have pointed out, there are several functional projections above VP, giving us two or three "fields" for scrambling. Details of the differences between the various proposals aside, it seems necessary to assume at least a number of topic phrases (TopP) above VP, constituting a field for scrambling which may also contain at most one Focus Phrase (FocP). Also, there is, of course, still the VP proper which is a field for (VP-internal) scrambling. Following Frey (2000), one may in addition assume scrambling to a field between the sentence adverbial and a temporal adverbial at the left periphery of the VP.

(12) (at least) three scrambling- "fields":

$$
\left[\mathrm{CP}_{?}\left[\mathrm{TopP}^{*} \text { (FocP) TopP }{ }_{?}\left[\mathrm{Sadv} \ldots,\left[\text { TempAdv }{ }_{\text {vp }}[(\mathrm{SU}) \ldots]\right]\right]\right]\right.
$$

I shall not be concerned with a detailed analysis; for valuable observations and their theoretical implications cf. Frey (2000). For my present purpose, it suffices to point out, following Frey (2000), that the Topic Phrases in (12) are to be interpreted not as 'familiarity'-topics but as 'aboutness'-topics. This is immediately made clear by the example (13), taken from Frey (2000). Here, the context given in (13) provides for an 'aboutness'-interpretation of the NP Otto. The following sentence (13a) complies with this, as Otto is in an ('aboutness')-topic position. (13b) is not a proper successor for (13) since Otto in (13b) is not an 'aboutness'-topic.

Ich erzähl dir mal was von Otto. ,Well, I'll tell you something about Otto.'

a. Nächstes Jahr wird Otto wahrscheinlich seine Kollegin heiraten. next yearwill Otto probably his colleague(fem.) marry 'Next Year, Otto will probably marry his colleague.'

\# Nächstes Jahr wird wahrscheinlich Otto seine Kollegin heiraten. next year will probably Otto his colleague marry

From the assumption that we are dealing with 'aboutness'-topics, it follows immediately that non-referring expressions like keiner ('nobody'), not being 'aboutness'-topics, cannot appear in this position.

If this is basically correct, as I assume, the possibility of a generic interpretation of NPs which have been scrambled to a topic-position follows: If an indefinite NP is scrambled to a topic-position, it becomes an 'aboutness'-topic, the rest of the sentence being a comment on this topic. In other words, a topic-comment structure establishes a kind of secondary prediction. The comment itself, containing the primary predication (subject-predicate, possibly represented inside the VP) has to make sense w.r.t. the topic it is about. Thus, a scrambled generic NP requires, of course, a generic comment, as in (14a). 
(14) a. weil Väter natürlich oft mit ihren Kindern spielen. (GEN) since fathers naturally often with their children play

'Since fathers do of course often play with their children.'

If this analysis is correct it does not follow however that a NP which is scrambled to a topic-position must be interpreted as generic. Thus, given a proper specific comment, the scrambled NP should also be interpretable with a specific existential reference, as (14b), I believe, shows.

b. weil Väter natürlich auch gestern mit ihren Kindern spielten. ( $\exists$, specific) Since fathers naturally also yesterday with their children played

'Since also yesterday fathers played with their children.'

Notice that in my present analysis this is predicted whereas with a bi-partition analysis along the lines of (7a) a generic reading is stipulated, and an existential reading for a scrambled NP is ruled out. The same holds for my previous analysis (7b) since the reference of a scrambled NP in the B-part of the sentence (referring to background knowledge) has to be taken to be established, hence an existential reading should not be possible. I conclude, thus, that the restriction on the scrambling of indefinites as given above is wrong. The correct restriction seems to be (15):

a. don't scramble indefinites inside the VP (=this follows from referential dependency)

b. indefinites which are scrambled to the topic-position are only allowed if they can be interpreted as referentially independent from referential expressions which they c-command in the scrambling position.

Both parts of this condition follow from a proper theory of referential dependency together with a proper theory of topic-comment-structure and its interpretation. Details of both theories will of course have to be worked out.

In the rest of this paper, I will discuss some ramifications and some possible consequences of a theory of referential dependency.

As pointed out above, scrambling across a subject is ungrammatical in most cases, cf. (16).

$$
\begin{aligned}
& \text { *weil Eisbären natürlich Paul gestern fotografierte. } \\
& \text { Since polar bears }(A C C) \text { naturally Paul yesterday took-pictures-of }
\end{aligned}
$$

This statement has to be relativized, however, given examples like (17).

$$
\text { weil Eisbären natürlich alle mögen / niemand mag. (GEN) }
$$

Since polar bears(ACC) naturally all like / nobody likes

'Since, naturally, everybody / nobody likes polar bears.'

Here a subject NP with a universal quantifier (alle 'everybody') or a negated existential quantifier (niemand, 'nobody') does not block scrambling of the indefinite NP Eisbären ('polar bears'). It cannot be the generic quality of the subject NP as such 
which allows for scrambling, as (18) shows, where the generic indefinite NP Eisbären ('polar bears') has been scrambled across the generic subject NP ein Eskimo ('an Eskimo').

*weil Eisbären natürlich ein Eskimo gerne jagt. since polar bears naturally an Eskimo gladly hunts 'since an Eskimo likes to hunt polar bears.'

The facts are far from clear especially as one tends to utter sentences like (17) or (18) with a bridge accent, stressing the scrambled NP (Eisbären) as well as the subject NP (alle, keiner, ein Eskimo). This specific intonation pattern seems to 'rescue' the sentences. (For details of a proper analysis of bridge accent structures cf. Büring 1997, among others). With normal sentence intonation, however, (18) seems to me to be ungrammatical. What would follow along the lines of explanation which I suggested is the following:

While (17) is a possible topic-comment structure, (18) is not. In (17), a kind of 'secondary predication' is made of polar bears in general: Everybody/nobody likes them. In (18) however, the comment on the topic phrase Eisbären does not seem reasonable: It does not make much sense to assert of polar bears that in general it is true that any (generic) Eskimo has the property of liking to hunt them. So, again, an explanation for the constraint to scramble across referentially restricted subjects (as in (18), as opposed to (17) with subject NPs which are not restricted referentially) relies on a proper theory of referential dependency and a proper theory of topic-comment structure and its interpretation.

Another observation concerns the order of arguments in the topic field. As Meinunger (2000) points out, Rizzi's (1997) proposal of a series of topic phrases wedged in between the functional projections $\mathrm{CP}$ on the left and possibly IP or some part of it on the right, cf. (12), has to be revised: Meinunger analyzes the Topic Phrases as Agreement Phrases. Their unmarked hierarchical order seems to be the same as inside the VP, as $(19 \mathrm{a}, \mathrm{b}, \mathrm{c})$ show.

(19) a. weil Paul seiner Freundin Schmuck natürlich gerne schenkt. since Paul his-DAT girl-friend jewelleyr $(A C C)$ naturally gladly donates 'Since Paul likes to give his girl friend jewellery'

b. *weil Paul Schmuck seiner Freundin natürlich gerne schenkt since Paul jewellery $(A C C)$ his-DAT girl-friend naturally gladly donates

c. *weil Schmuck Paul seiner Freundin natürlich gerne schenkt. Since jewellery $(A C C)$ Paul his-DAT girl-friend naturally gladly donates

All the arguments in these sentences are scrambled across the sentence adverbial natürlich ('naturally'), thus above the VP-projection. If their ordering violates the unmarked order $S V>I O>D O$, as in $(19 b, c)$, the sentence is ungrammatical. If this is true, it indicates strongly that referential dependency does not only apply inside the VP but inside the whole 'middle field' of German sentences, i.e. to the whole part of the sentence below the CP.

The initial field, however, does not seem to participate in the overall relationship of c-commanding referential dependency. Thus, a NP in SpecCP retains its referential dependency from its original position. Hence, movement to SpecCP does not have to obey the restrictions which hold for scrambling; consequently, any NP (or any other 
maximal projection) may be placed in the initial field no matter where its source in the base structure is. This can be shown quite clearly if we consider possessive phrases, a good example of referential dependency. A possessive pronoun may refer to a $c$ commanding NP only in the unmarked order (20a):
a. Gestern hat tatsächlich (der) Peter ${ }_{\mathrm{i}}$ seinen $_{\mathrm{i}}$ yesterday has actually (the-NOM) Peter ${ }_{i}$ his ${ }_{i}-A C C$ brother praised 'Yesterday, Peter actually praised his brother.'
b. * Gestern hat tatsächlich seinen ${ }_{\mathrm{i}}$ Bruder (der) Peter ${ }_{\mathrm{i}}$ gelobt. yesterday has actually his ${ }_{i}$-ACC brother the-NOM Peter praised
c. *Gestern hat seinen ${ }_{\mathbf{i}} \quad$ Bruder tatsächlich der Peter ${ }_{\mathbf{i}}$ gelobt. Yesterday has his $_{i}$-ACC brother actually the-NOM Peter praised $^{-}$
d. Seinen $_{\mathrm{i}}$ Bruder hat (der) Peter ${ }_{\mathrm{i}}$ gestern gelobt. His $_{i}$-ACC brother has the-NOM Peter; yesterday praised

If the possessive phrase is scrambled, as in $(20 \mathrm{~b}, \mathrm{c})$, it looses its co-reference with a NP across which it has been scrambled. If, however, the possessive phrase is moved to the initial position as in (20d), it retains the possibility of co-reference with the subject NP across which it has been moved. (Non-co-referential readings of the possessive pronoun are possible throughout since they do not show the kind of (co)-referential dependency requiring the corresponding $\mathrm{c}$-command relations.)

A closer look reveals, however, that the conditions are a little more complicated if we consider the interaction with adverbials. If my judgement is correct, then movement of an object NP to the sentence initial position seems only possible if the subject has been scrambled from its VP-internal position, as the examples in (21a-c) show.
a. Eisbären
hat Paul natürlich immer geliebt.
polar bears(ACC) has Paul naturally always loved
b.
Eisbären
polar bears $(A C C)$
always loved them
c. $\quad$ Eisbären
polar bears $(A C C)$ hat natürlich Paul immer geliebt.
has naturally Paul always loved polar bears(ACC) has naturally always Paul loved

The case is different if the subject is moved to SpecCP as in (22). In this case the object Eisbären 'polar bears' may either remain inside the VP (22a) or be scrambled to a topic position (22b).
b. Paul hat natürlich immer Eisbären
Paul has naturally always polar bears (ACC) loved
a. Paul hat Eisbären natürlich immer geliebt.
Paul has polar bears(ACC) naturally always loved
'Paul has of course always loved polar bears.'

Still, both sentences seem to have a slightly different interpretation. What comes to mind in the present discussion is the idea that here, too, referential dependency plays a role. For the cases in (21), my explanation would be as follows: Let us assume a referential dependency between the subject and the temporal adverbial. If the definite 
subject Paul stays in its base position inside the VP, as in (21a), the temporal adverbial immer ('always') is not restricted referentially. Thus, (21a) would have the interpretation that for all times in the universe it be true that the specific individual Paul loves polar bears, clearly not a reasonable assertion, given that individuals like Paul only live for a specific period of time. In (21b), however, the temporal adverbial is referentially dependent from the scrambled subject which c-commands it from its topic position. In this case, immer ('always') may only refer to all times available to Paul, as it were, giving the intended interpretation. Similar considerations will apply to the slight difference in meaning between (22a) and (22b). Whatever the details of the analysis will turn out to be, what (21) and (22) show us is that there exists some paradoxical kind of interaction between scrambling and movement to SpecCP which has to be investigated in more detail: A temporal adverbial seems to be referentially dependent from a subject in SpecCP. This looks as if movement to SpecCP presupposes scrambling to a topic position in which the required referential dependency is established. On the other hand, an object in SpecCP seems to retain its referential dependency from its base position.

As regards possessive phrases, they also show that it is necessary to assume such an interaction between scrambling and movement to the initial position. As (23a) shows, scrambling of the definite IO dem Otto ('the-DAT Otto') to a topic position enables us to interpret the subject NP sein Vater ('his father') with a co-referent possessive pronoun, as indicated by the indices. This is not possible for $(23 \mathrm{~b})$. Here, the subject is scrambled to a topic position in which its possessive pronoun is not c-commanded by the co-referential NP Otto, hence cannot be interpreted as referentially dependent. (Again, as in (20), non-co-referential readings are possible.)

a. Allerdings wird dem $\mathrm{Otto}_{\mathbf{i}}$ wahrscheinlich $\operatorname{sein}_{\mathbf{i}}$ Vater $\mathbf{t}$ das Auto

ausleihen.

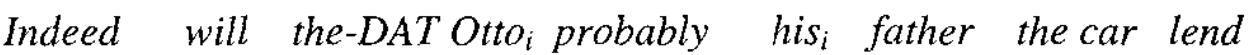
'Indeed, Otto's father will probably lend him the car.'

b. *Allerdings wird $\operatorname{sein}_{\mathrm{i}}$ Vater wahrscheinlich $\mathbf{t}$ dem Otto $\mathrm{O}_{\mathbf{i}}$ das Auto Indeed will his $s_{i}$ father probably the-DAT-Otto ${ }_{i}$ the caur leihen.
a. $\operatorname{Sein}_{\mathrm{i}}$ Vater wird dem Otto $_{\mathrm{i}}$ wahrscheinlich $\mathbf{t}$ das Auto ausleihen.

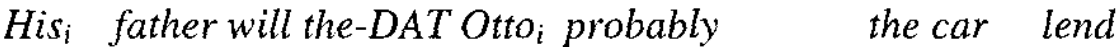 'Probably, Otto's father will lend him the car.'
b. $\quad{ }^{*} \operatorname{Sein}_{\mathrm{i}}$ Vater wird wahrscheinlich $\mathbf{t}$ dem Otto $_{\mathrm{i}}$ das Auto ausleihen. $\mathrm{His}_{i}$ father will probably the-DAT Otto ${ }_{i}$ the car lend

Fronting of the possessive phrase in $(24 a)$ is possible with the co-referential reading. Given the scenario I assumed so far, this is explained if we assume the structure indicated by the trace in the VP-internal subject position, i.e. if we assume an underlying structure with the IO scrambled to a topic position. (24b), however, is ungrammatical with a co-referential reading. This would be explained if we assume an underlying structure in which the fronted phrase originates in the position indicated by the trace.

Many puzzles remain. What the preceding discussion of but a few cases of referential dependency, however, shows, to my mind, is that the area of application of the concept 
of referential dependency is quite diversified and the crucial facts are as yet not understood very well at all. Furthermore, it seems to me, the very general concept of referential dependency, if correct, may also be relied upon to derive the property and position of personal pronouns and other referential expressions. Hence, binding theory and a proper theory of the interaction of quantifiers may eventually turn out to follow from a general theory of referential dependency yet to be elaborated.

\section{References:}

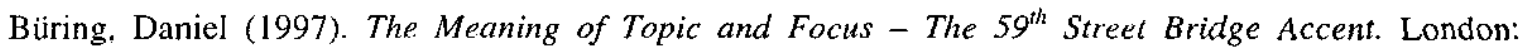
Routledge.

Büring, Daniel. forthcoming. Let's Phrase It! - Focus, Word Order, and Prosodic Phrasing in German Double Object Constructions. Competition in Syntax, edited by Gereon Müller and Wolfgang Sternefeld, 101-137. Amsterdam: Benjamins.

Double Object Constructions. In: Müller, Gereon/Sternefeld Wolfgang (eds.) (2001) Competition in Syntax, 69-105.

Diesing. Molly (1990). The Syntactic Roots of Semantic Partition. PhD. Diss. U of Mass. Amherst.

Frey, Werner (2000). Über die syntaktische Position der Satztopiks im Deutschen. In: ZAS Papers in Linguistics 20, 137-172.

Frey, Werner/Pittner, Karin (1998). Zur Positionierung der Adverbiale im deutschen Mittelfeld. In: Linguistische Berichte 176, 489-534.

Haider, Hubert/Rosengren, Inger(1998). Scrambling. Universität Lund (=Sprache und Pragmatik. Arbeitsberichte 49).

Heusinger, Klaus von (1997). Salienz und Referenz: Der Epsilonoperator in der Semantik der Nominalphrase und anaphorischer Pronomen. (Studia Grammatica 43) Berlin: Akademie-Verlag.

Heusinger, Klaus von (1999). Intonation and Information Structure. Habilitationsschrift, University of Konstanz.

Lenerz, Jürgen (1977). Zur Abfolge nominaler Satzglieder im Deutschen. Tübingen: Narr.

Lenerz, Jürgen (2001.) Word Order Variation: Competition or Co-Operation? In: Müller, Gereon/Sternefeld, Wolfgang (2001) Competition in Syntax. Berlin, New York: Mouton de Gruyter, 249-281.

Meinunger, André (2000). Syntactic Aspects of Topic and Comment. Amsterdam/Philadelphia: John Benjamins.

Rizzi, Luigi (1997). The fine structure of the left periphery. In: Haegemann, Liliane (1997) Elements of grammar: handbook in generative syntax. Dordrecht: Kluwer, 281-337. 